\title{
RNASET2 is required for ROS propagation during oxidative stress-mediated cell death
}

\author{
G Caputa ${ }^{1}$, S Zhao ${ }^{1}$, AEG Criado ${ }^{1}$, DS Ory ${ }^{1}$, JG Duncan ${ }^{2}$ and JE Schaffer, ${ }^{*}, 1$
}

RNASET2 is a ubiquitously expressed acidic ribonuclease that has been implicated in diverse pathophysiological processes including tumorigeneis, vitiligo, asthenozoospermia, and neurodegeneration. Prior studies indicate that RNASET2 is induced in response to oxidative stress and that overexpression of RNASET2 sensitizes cells to reactive oxygen species (ROS)-induced cell death through a mechanism that is independent of catalytic activity. Herein, we report a loss-of-function genetic screen that identified RNASET2 as an essential gene for lipotoxic cell death. Haploinsufficiency of RNASET2 confers increased antioxidant capacity and generalized resistance to oxidative stress-mediated cell death in cultured cells. This function is critically dependent on catalytic activity. Furthermore, knockdown of RNASET2 in the Drosophila fat body confers increased survival in the setting of oxidative stress inducers. Together, these findings demonstrate that RNASET2 regulates antioxidant tone and is required for physiological ROS responses.

Cell Death and Differentiation (2016) 23, 347-357; doi:10.1038/cdd.2015.105; published online 24 July 2015

Obesity, metabolic syndrome, and diabetes are increasingly prevalent causes of morbidity and mortality worldwide. Complications are common in these disorders and are linked to delivery of excess glucose and fatty acids to tissues in which these substrates lead to pathophysiological metabolic fluxes and signaling cascades. For example, ectopic lipid accumulation in the liver, skeletal muscle, pancreatic islets, and heart is associated with non-alcoholic steatohepatitis, insulin resistance, $\beta$-cell dysfunction, and cardiomyopathy, respectively. ${ }^{1-4}$ Beyond lowering serum lipid levels, strategies to prevent this lipotoxicity are hampered by our incomplete knowledge of the cellular pathways engaged by these metabolites when they are present in excess.

In vivo and in vitro studies have revealed that accumulation of excess lipids in non-adipose cells precipitates many changes in gene expression and signaling cascades upstream of cell death. ${ }^{5-9}$ Compensatory incorporation of lipids into new membrane synthesis or triglyceride stores are likely to be initially protective,$^{10,11}$ but ultimately prove maladaptive because of the deleterious consequences of altered membrane composition on organelle function, ${ }^{12}$ and because lipids may ultimately be mobilized from inert pools during prolonged exposure. ${ }^{13}$ Similarly, whereas engagement of the endoplasmic reticulum (ER) stress machinery or generation of reactive oxygen species (ROS) can serve adaptive or productive signaling functions in response to lipid overload, extreme ER and oxidative stress engage cell death pathways. ${ }^{14-17}$ The importance of oxidative stress in the pathophysiological response to substrate excess is underscored by observation that treatment with chemical antioxidants and overexpression of ROS-scavenging enzymes mitigates against lipotoxic cell death and against diabetic complications in animal models. ${ }^{18-21}$

To identify critical mediators of lipotoxic cell death, our laboratory has focused on characterizing genes identified through a loss-of-function genetic screen in mammalian fibroblasts. We found that cells become resistant to death from lipotoxic and generalized oxidative stress stimuli upon disruption of small nucleolar RNAs (snoRNAs) encoded within the ribosomal protein L13a ( $r p L 13 a$ ) locus or disruption of expression of a splicosomal protein necessary for production of these non-coding RNAs from intron lariats. ${ }^{22,23}$ The mechanism of action of these non-coding RNAs is an area of active investigation. Herein, we describe findings from a completely independent mutant isolated from this genetic screen in which an allele encoding RNASET2 was disrupted. This ribonuclease was initially of interest because of a potential link to production of the rp/13a snoRNAs. However, our studies show that RNASET2 acts upstream of these non-coding RNAs by influencing cellular and organismal susceptibility to oxidative stress.

\section{Results}

RNASET2 haploinsufficiency confers resistance to palmitate-induced cell death. To identify genes that are critical for the cellular response to lipotoxicity, we performed a genetic screen in Chinese hamster ovary $(\mathrm{CHO})$ cells using

\footnotetext{
${ }^{1}$ Diabetic Cardiovascular Disease Center, Department of Internal Medicine, Washington University School of Medicine, St. Louis, MO, USA and ${ }^{2}$ Department of Pediatrics, Washington University School of Medicine, St. Louis, MO, USA

*Corresponding author: J Schaffer, Diabetic Cardiovascular Disease Center, Washington University School of Medicine, 660 South Euclid Avenue, Campus Box 8086, St. Louis 63110, MO, USA. Tel: +1 314362 8717; Fax: +1 314747 0264; E-mail: jschaff@ wustl.edu

Abbreviations: BODIPY FA, 4,4-difluoro-5,7-dimethyl-4-bora-3a,4a-diaza-s-indacene-3-hexadecanoic acid; $\mathrm{CHO}$, Chinese hamster ovary; $\mathrm{Cl}$, catalytically inactive; $\mathrm{DCF}$, 2',7'-dichlorodihydrofluorescein diacetate; DHE, dihydroethidium; ER, endoplasmic recticulum; palm, palmitate; PI, propidium iodide; qRT-PCR, quantitative real-time PCR; RACE, rapid amplification of cDNA ends; ROS, reactive oxygen species; rpL13a, ribosomal protein L13a; rRNA, ribosomal RNA; scr, scrambled; shRNA, short hairpin RNA; snoRNA, small nucleolar RNA; TEAC, Trolox equivalent antioxidant capacity assay; tRNA, transfer RNA; UT, untreated; WT, wild type

Received 26.2.15; revised 23.6.15; accepted 25.6.15; Edited by E Gottlieb; published online 24.7.15
} 
the ROSA $\beta$ geo retroviral promoter trap to generate mutants, as previously described. ${ }^{24}$ The promoterless proviral $\beta$ galactosidase-neomycin cassette confers antibiotic resistance only when it integrates downstream of an actively transcribed RNA polymerase II promoter, resulting in a fusion transcript that contains host and viral neomycin phosphotransferase sequences. $\mathrm{CHO}$ mutants were selected by growth in G418 and subsequently challenged by growth in media supplemented with $500 \mu \mathrm{M}$ palmitate (palm) for $48 \mathrm{~h}$, which has been shown to cause lipotoxic cell death in wild type (WT) cells (Figure 1a). ${ }^{18}$ Herein, we focus on a novel, independently isolated mutant, the $2 \mathrm{~B} 1$ cell line.

Our screen was performed with viral transduction at low multiplicity of infection to facilitate single gene disruptions. Southern analysis of genomic DNA from $\mathrm{CHO}$ and 2B1 cells revealed a single band in $2 \mathrm{~B} 1$ cells that hybridized to a radiolabeled probe against viral sequences (Figure $1 \mathrm{~b}$ ). This result is consistent with a single integration of the ROSAßgeo insert in 2B1 cells. We next directly compared cell death responses in $\mathrm{CHO}$ and 2B1 cells. The 2B1 line was significantly resistant to palm-induced cell death and apoptosis, as assessed by propidium iodide (PI) and annexin $\mathrm{V}$ staining, respectively (Figure $1 \mathrm{c}$ and $\mathrm{d}$ ). However, when treated with the general inducers of apoptosis, staurosporine, and actinomycin D, 2B1 cells were indistinguishable from the parental $\mathrm{CHO}$ cells with respect to the extent of cell death.
This indicates that the 2B1 cells are resistant to lipotoxicity, but not generally resistant to cell death. Resistance to lipotoxicity in 2B1 cells was not simply the result of failure to take up fatty acids, because uptake of a fluorescent palm analog was indistinguishable between 2B1 and WT cells (Figure 1e).

We utilized the proviral fusion transcript to identify the disrupted locus in 2B1 cells. mRNA isolated from 2B1 cells was used for $5^{\prime}$ rapid amplification of cDNA ends (RACE), and sequencing of the RACE product identified the gene for RNASET2 as the site of integration (Figure 2a). RNASET2 is an acidic endoribonuclease that belongs to the T2 family of RNases implicated in diverse cellular functions. ${ }^{25}$ PCR analysis of cDNA from $\mathrm{CHO}$ and 2B1 cells confirmed that ROSAßgeo had inserted into the RNASET2 locus in 2B1 cells (Figure 2b). Reactions using a forward RNASET2 primer and a reverse ROSA $\beta$ geo primer produced a product corresponding to the fusion transcript in $2 \mathrm{~B} 1$, but not $\mathrm{CHO}$ cells, consistent with proviral integration only in the mutant. Reactions using forward and reverse RNASET2 primers produced a product of the expected size in both $\mathrm{CHO}$ and 2B1 cells, indicating that the 2B1 cells retain an intact allele in addition to the disrupted allele. To evaluate the consequences of disruption of an allele for RNASET2, we quantified RNASET2 mRNA in CHO and 2B1 cells under basal growth conditions and following lipotoxic stress (Figure 2c). Expression of RNASET2 was indistinguishable between these cell lines under normal growth conditions. a
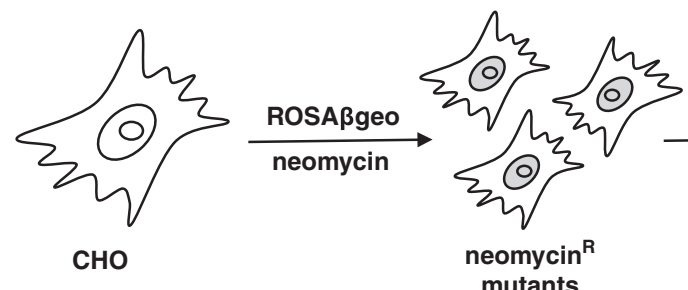

mutants

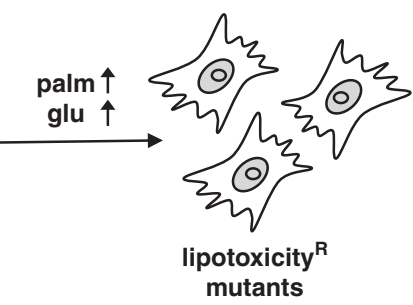

mutants
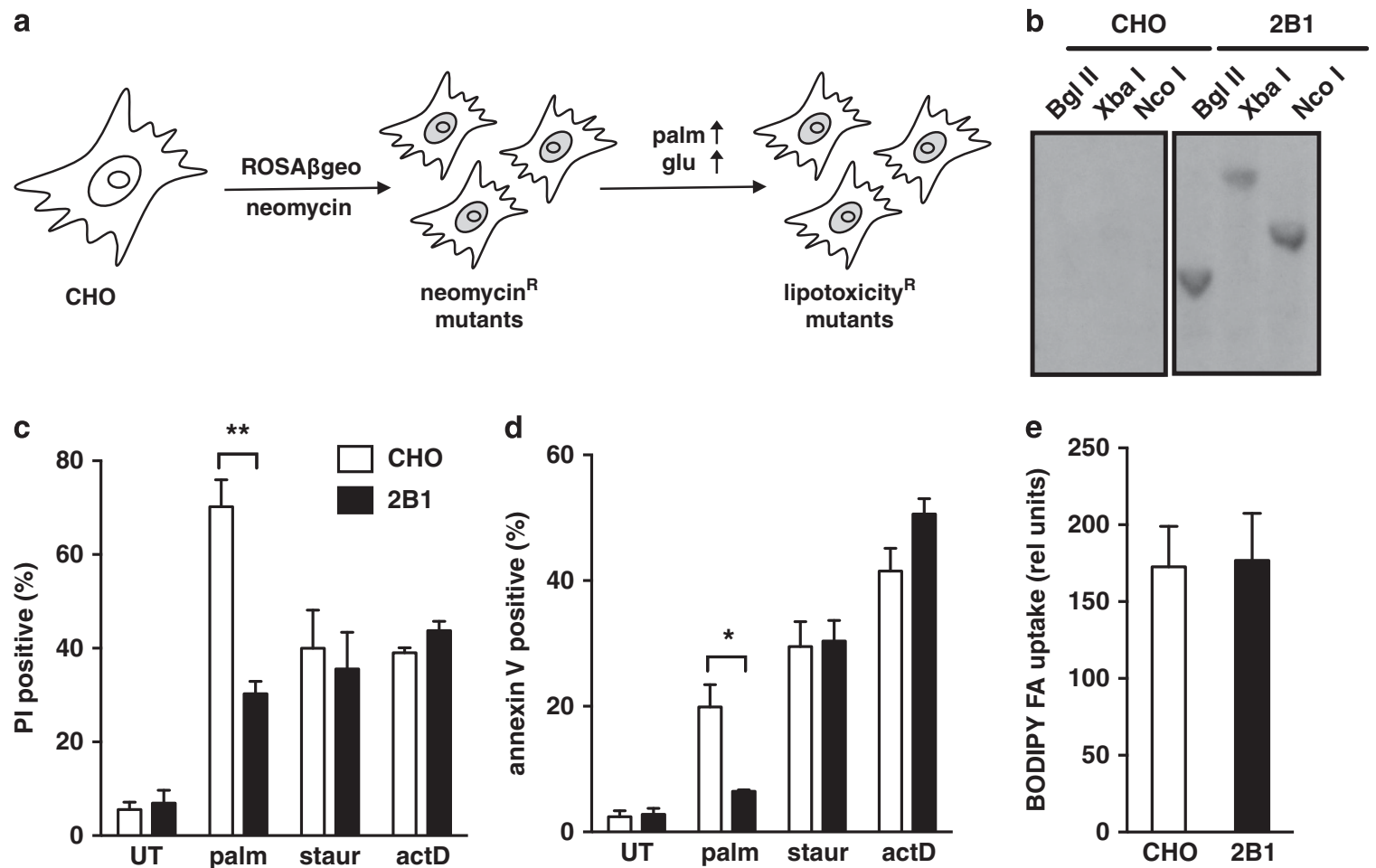

Figure $12 \mathrm{~B} 1$ cells are resistant to metabolic stress. (a) Wild-type $(\mathrm{CHO})$ cells were mutagenized by transduction with the ROSA $\beta$ geo retroviral promoter trap, and mutants were selected by treatment with neomycin. Palmitate-resistant mutants were subsequently selected by growth in high-glucose (glu) media supplemented with $500 \mu \mathrm{M}$ palmitate (palm) for $48 \mathrm{~h}$. (b) $\mathrm{CHO}$ and 2B1 mutant genomic DNA was digested with restriction enzymes Bgl II, Xba I, or Nco I, and Southern blot was hybridized with a ${ }^{32} \mathrm{P}$-labeled probe against the integrated ROSA $\beta$ geo retroviral sequence. (c, d) CHO (open bars) and 2B1 mutant (filled bars) cells were treated with $500 \mu \mathrm{M}$ palm for $48 \mathrm{~h}$ or with $80 \mathrm{nM}$ staurosporine (staur) or $2 \mu \mathrm{M}$ actinomycin D (actD) for $24 \mathrm{~h}$. Cell death was assayed by propidium iodide (PI) staining (c) and apoptosis was assessed by simultaneous annexin $\mathrm{V}$ and PI staining (d) with flow cytometric analysis of $10^{4}$ cells/sample and a minimum of $n=3$ samples for each condition. Data is expressed as mean fluorescence+standard error (S.E.) (e) $\mathrm{CHO}$ and 2B1 mutant cells were incubated with BODIPY-labeled fatty acid (BODIPY FA) for $1 \mathrm{~min}$. Uptake was measured by flow cytometric analysis of $10^{4} \mathrm{cells} / \mathrm{sample}$, with $n=3$ samples for each cell type. Data are expressed as mean fluorescence+S.E. (relative (rel) units). ${ }^{*} P<0.05,{ }^{* *} P<0.005$ for $2 \mathrm{~B} 1$ versus $\mathrm{CHO}$ 


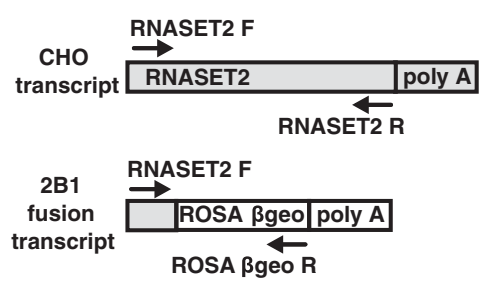

b

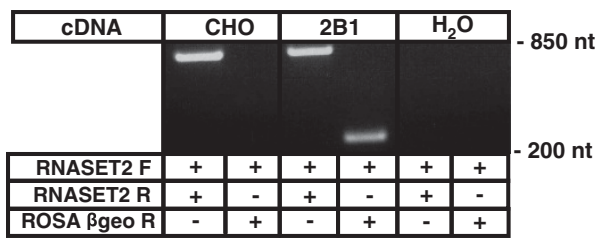

C

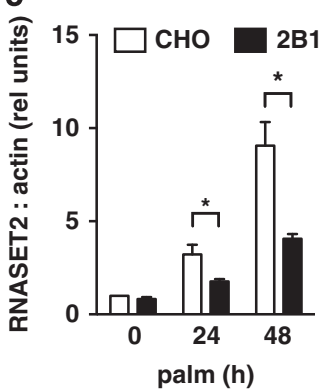

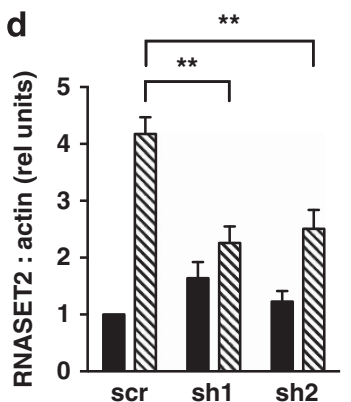
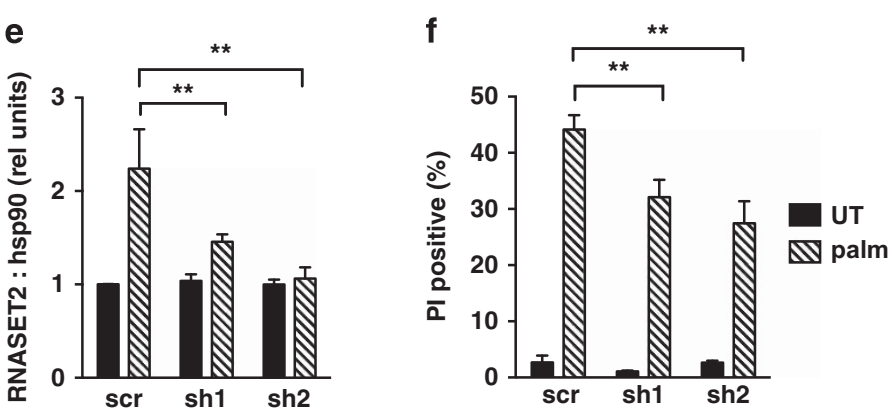

Figure 2 Haploinsufficiency for RNASET2 protects cells from lipotoxicity. (a) Diagram shows intact RNASET2 transcript in CHO cells, fusion transcript in 2B1 cells, and forward (F) and reverse (R) primers for PCR amplification of each (arrows). ROSA $\beta$ geo sequences are white and RNASET2 sequences are shaded. (b) PCR analysis of cDNA from $\mathrm{CHO}$ and $2 \mathrm{~B} 1$ cells or no $\mathrm{CDNA}\left(\mathrm{H}_{2} \mathrm{O}\right.$ as control) used primers as indicated in a. Products were analyzed by agarose gel electrophoresis and EtBr staining. (c) RNA was isolated from $\mathrm{CHO}$ (open bars) and 2B1 (filled bars) cells grown in media supplemented with $500 \mu \mathrm{M}$ palm for 0 , 24, or $48 \mathrm{~h}$. RNASET2 expression relative to $\beta$-actin was determined by qRT-PCR. (d-f) C2C12 murine myoblasts were transfected with short hairpin RNA (sh) sequences targeting RNASET2 or a scrambled (scr) control, and independent stable clonal lines were isolated. Cells were maintained in growth media (untreated, UT, filled bars) or supplemented with $500 \mu \mathrm{M} \mathrm{palm}$ for $16 \mathrm{~h}$ (hatched bars) prior to analysis. RNA was isolated and analyzed by qRT-PCR for RNASET2 relative to $\beta$-actin (d). RNASET2 protein levels were analyzed by western blotting of total cell lysates. Graph shows mean densitometry of RNASET2 species normalized to hsp90 as a loading control for each condition/cell type (e). Cell death was quantified by PI staining and flow cytometric analysis. Graph shows mean fluorescence+S.E. for $10^{4}$ cells/sample (f). All data are reported as mean+S.E. for a minimum of $n=3$ samples per condition/cell type. ${ }^{*} \mathrm{P}<0.05$ for $2 \mathrm{~B} 1$ versus $\mathrm{CHO} ;{ }^{* *} P<0.05$ for palm-treated sh versus scr

RNASET2 transcript was induced under lipotoxic conditions in both cell types, although induction was significantly blunted in the 2B1 mutant. Together, our observations are consistent with a model in which integration of the ROSA $\beta$ geo provirus disrupted one of two alleles for RNASET2, and in which 2B1 cells represent a model of RNASET2 haploinsufficiency. In the 2B1 cells, the remaining allele for RNASET2 is apparently adequate to support basal expression, but it is not sufficient to support induction of expression to WT levels under stress conditions.

To confirm the role of RNASET2 in lipotoxicity, we tested whether targeted loss-of-function in an independent cell type also conferred resistance to palm. We isolated stable $\mathrm{C} 2 \mathrm{C} 12$ murine myoblast cell lines that expressed either control, scrambled (scr) short hairpin RNAs (shRNAs), or shRNAs targeting RNASET2 and assayed for RNASET2 expression and cell death following palm treatment. Similar to our findings in $\mathrm{CHO}$ cells, RNASET2 was transcriptionally induced with palm treatment in $\mathrm{C} 2 \mathrm{C} 12$ cells, and two independently isolated clonal cell lines showed 46\% (sh1) and 40\% (sh2) knockdown under palm-treated conditions relative to control (Figure 2d). RNASET2 protein production was also induced with palm treatment, and this induction was blunted in the RNASET2 shRNA knockdown cell lines compared with the control cell line (Figure 2e). The lines with RNASET2 knockdown showed significantly less palm-induced cell death compared with the scr control cell line (Figure 2f). These data provide independent confirmation that diminished expression of RNASET2 confers resistance to lipotoxic cell death.

Expression of catalytically active RNASET2 complements the 2B1 phenotype. Several reports have described biological roles for T2 family members that are independent of catalytic activity. ${ }^{26-28}$ To determine whether catalytic activity is required for the role of RNASET2 in lipotoxicity, we carried out complementation studies. A catalytically inactive (CI) murine RNASET2 construct was generated through site-directed mutagenesis of two of the three catalytic histidines. ${ }^{29,30}$ Transient overexpression of both WT and $\mathrm{Cl}$ murine constructs in $\mathrm{CHO}$ cells produced glycosylated, mature RNASET2 protein, recognized by an antiserum specific for the murine protein (Figure 3a). Zymography confirmed that only the WT construct had functional RNase activity at the permissive $\mathrm{pH}$ of 5 . Independent 2B1 clonal cell lines stably expressing varying levels of either WT or $\mathrm{Cl}$ murine RNASET2 mRNA (Figure 3b) and protein (Figure 3c) were then isolated. 2B1 cells were protected from palminduced cell death, and this was not affected by transfection with empty vector (Figure 3d). Only WT, but not CI, RNASET2 overexpression increased palm-induced cell death when compared with empty vector, despite comparable or higher levels of expression of the $\mathrm{Cl}$ construct. These results further confirm the role for RNASET2 in palm sensitivity, and indicate that this function is dependent on its catalytic activity. 

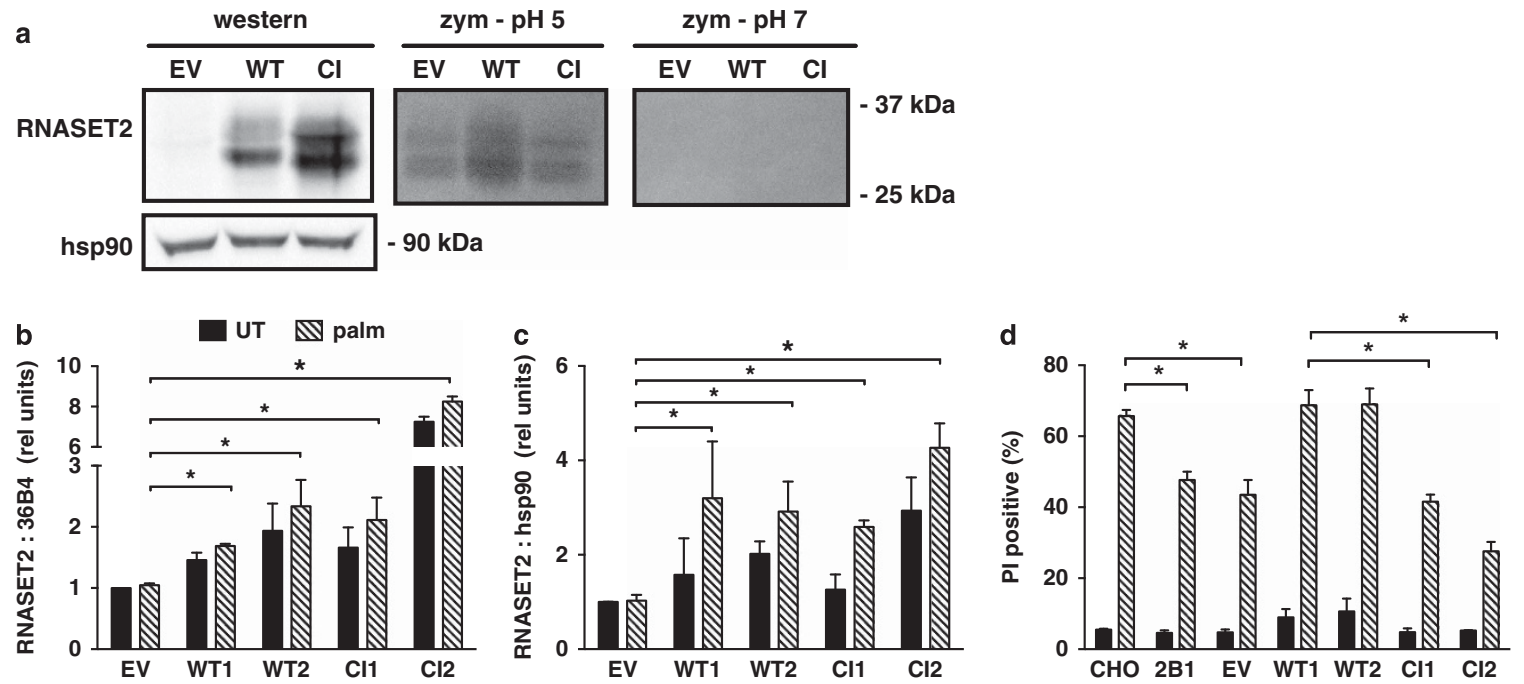

Figure 3 Catalytically active RNASET2 complements mutant 2B1 cells. (a) CHO cells were transiently transfected with empty vector (EV), wild type (WT), or catalytically inactive mutant $(\mathrm{Cl})$ murine RNASET2 sequences. Cells were analyzed by western blotting for expression of murine RNASET2 (antibody does not recognize hamster species) and hsp90 as a loading control, and by in-gel zymography (zym) for ribonuclease activity at pH 5 and pH 7 . For zymography panels, bands represent areas of enzymatic activity in RNA impregnated gel. Images are representative of three independent experiments. (b-d) Mutant 2B1 cells were transfected with EV or plasmids encoding WT or Cl murine RNASET2. Independent stable clonal cell lines were isolated for each construct and analyzed following growth in normal media (untreated, UT, black bars) or following supplementation with $500 \mu \mathrm{M}$ palm for $48 \mathrm{~h}$ (hatched bars). RNA was isolated and analyzed by qRT-PCR for RNASET2 expression relative to $36 \mathrm{~B} 4$ using primers specific for the murine RNASET2 transcript (b). RNASET2 protein levels were analyzed by western blotting of total cell lysates. Graph shows mean densitometry of RNASET2 species normalized to hsp90 (c). Cell death was assayed by PI staining and flow cytometric analysis on $10^{4}$ cells/sample (d). Data are expressed as mean+S.E. for a minimum of $n=3$ samples per condition/cell type. ${ }^{*} P<0.05$ for comparisons indicated

The expression of the transfected murine RNASET2 constructs was unaffected by palm, likely because the transfected sequences lacked control elements present in the endogenous RNASET2 locus.

2B1 cells fail to accumulate cytoplasmic rpL13a snoRNAs during lipotoxic stress. Our previous studies have shown that following exposure to lipotoxic conditions, snoRNAs from the rpL13a locus accumulate in the cytosol and function as essential mediators of cell death. ${ }^{22}$ Based on the requirement of RNase activity for complementation, we hypothesized that the biochemical function of RNASET2 during lipotoxicity might contribute to the biogenesis of the $r p L 13 a$ snoRNAs. To test this possibility, we compared RNASET2-deficient 2B1 and WT CHO cells for cytosolic accumulation of the rpL13a snoRNAs in response to palm treatment. Cytosolic extracts were isolated by differential detergent extraction, and snoRNAs were quantified by quantitative real-time PCR (qRT-PCR) (Figure 4a). In contrast to the parental $\mathrm{CHO}$ cells, RNASET2-deficient 2B1 cells have blunted and delayed accumulation of $r p L 13 a$ snoRNAs in the cytoplasm after palm treatment. To test whether cytoplasmic accumulation of the snoRNAs requires RNASET2 activity as well as protein, we quantified cytosolic snoRNAs in the 2B1complemented clones expressing either WT or CI RNASET2 following palm treatment (Figure 4b). Only 2B1 clones complemented with WT RNASET2, but not CI RNASET2, demonstrated cytoplasmic snoRNA accumulation, indicating that RNase activity is required for this function. To probe whether differences in cytoplasmic snoRNA accumulation reflect altered expression from the $r p L 13 a$ locus or a defect in snoRNA processing, we quantified the precursor pre-mRNA and intron lariats from which the snoRNAs are processed, and levels of the snoRNAs in the nucleus (Figure 4c-e). As judged by each of these measures, the 2B1 cells were indistinguishable from parental $\mathrm{CHO}$ cells, indicating that the mutant is capable of snoRNA production, but fails to accumulate WT levels of these non-coding RNAs in the cytosol under stress conditions.

RNASET2 is a mediator of ROS generation during lipotoxicity. ROS is an important signaling intermediate during lipotoxicity, given that pre-treatment with antioxidants decreases palm-induced ROS and cell death. ${ }^{24,31}$ The observation that treatment of cells with more direct inducers of oxidative stress, such as hydrogen peroxide, also causes cytoplasmic snoRNA accumulation suggests that ROS may be an upstream signal for the redistribution of snoRNAs. ${ }^{22}$ Because cells haploinsufficient for RNASET2 fail to accumulate the rpL13a snoRNAs in the cytoplasm, but have no apparent defect in the generation of these snoRNAs (that is, nuclear levels are unchanged), we tested whether haploinsufficiency of RNASET2 modulated the generation of ROS in response to palm. Following supplementation of the media with palm, we quantified cellular superoxide by dihydroethidium (DHE) staining, and cellular hydrogen peroxide by $2^{\prime}$, 7'-dichlorodihydrofluorescein diacetate (DCF) staining. In WT $\mathrm{CHO}$ cells, levels of superoxide increased as early as $2 \mathrm{~h}$ following palm exposure, and this ROS further increased with longer incubations (Figure 5a). Increased hydrogen peroxide was detected later, following 12 and $16 \mathrm{~h}$ of palm exposure (Figure $5 \mathrm{~b}$ ). By contrast, 2B1 cells failed to increase superoxide in response to palm and had markedly blunted increases in hydrogen peroxide at the later time points. 
a

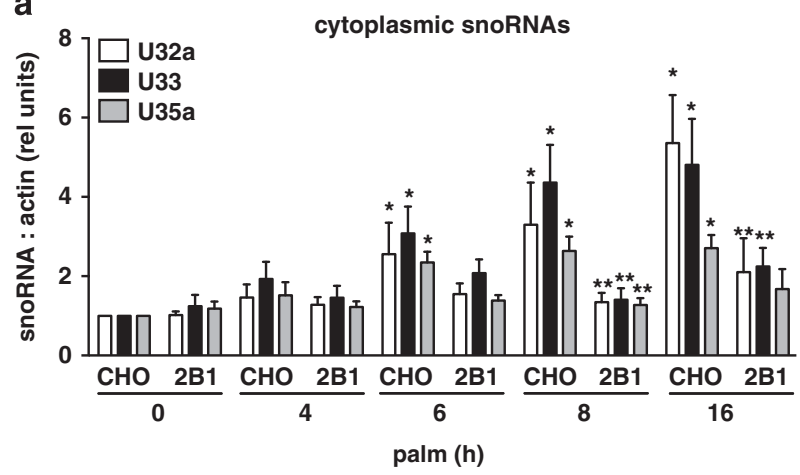

b

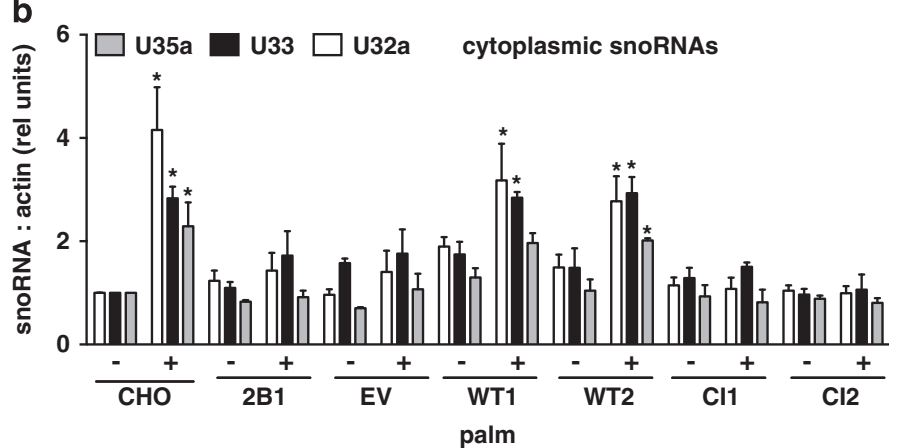

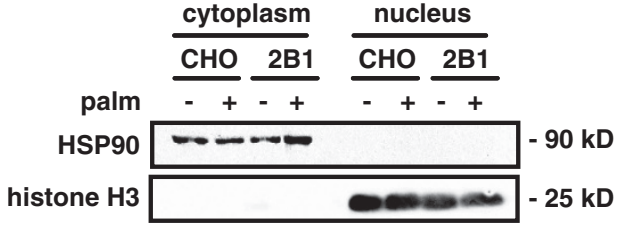

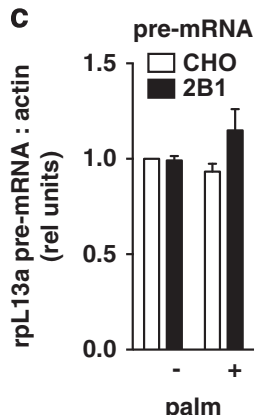

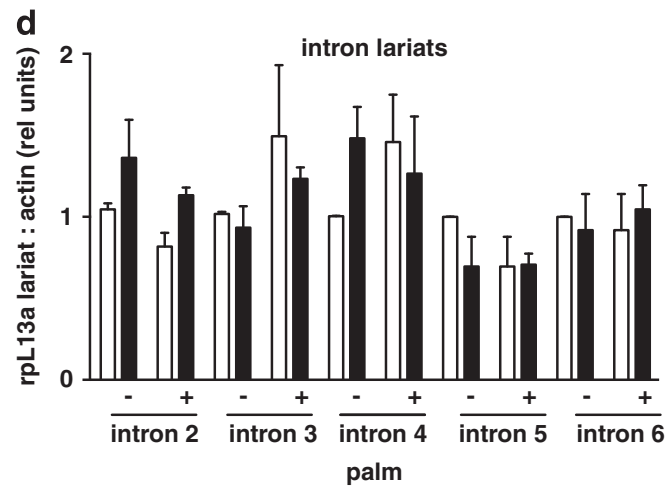

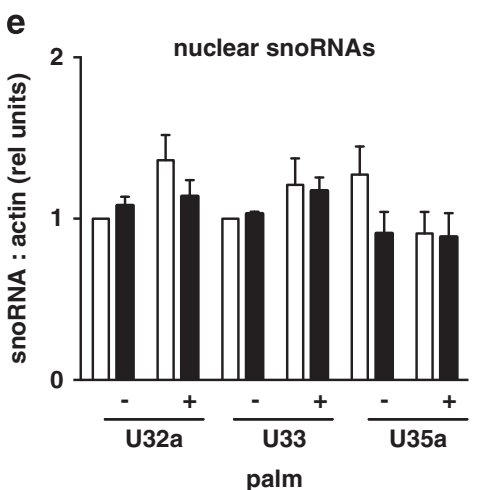

Figure 4 2B1 cells fail to accumulate rpL13a snoRNAs in the cytoplasm. (a) $\mathrm{CHO}$ and 2B1 cells were treated with $500 \mu \mathrm{M}$ palm for the indicated times. Cytoplasmic RNA was isolated by sequential detergent extraction, reverse transcribed, and analyzed by qRT-PCR for $r p L 13 a$ snoRNAs relative to $\beta$-actin. Graph (left) shows rpl13a snoRNA expression, and blots (right) show representative western analysis of fractions for hsp90 and histone $\mathrm{H} 3$ in cytosolic and nuclear fractions at $8 \mathrm{~h}$. (b) $\mathrm{CHO}, 2 \mathrm{~B} 1 \mathrm{cells}$ and $2 \mathrm{~B} 1 \mathrm{cells}$ stably transfected with EV or plasmids encoding WT or Cl murine RNASET2 (as in Figure 3) were treated with $500 \mu \mathrm{M}$ palm for $10 \mathrm{~h}$. Cytoplasmic RNA was isolated by sequential detergent extraction, reverse transcribed, and analyzed by qRT-PCR for rpL13a snoRNAs relative to actin (c-e). CHO (open bars) and 2B1 (filled bars) cells were untreated ( - ) or treated with palmitate for $9 \mathrm{~h}(+)$ and then fractionated by sequential detergent extraction. RNA from nuclear fractions was reverse transcribed and quantified by qPCR for premRNA (c), intron lariats (d), and nuclear snoRNAs (e), each relative to actin. Graphs report mean values+S.E. for $n=3$ independent experiments. ${ }^{*} P<0.05$ for treated versus untreated; ${ }^{* \star} P<0.05$ for $2 \mathrm{~B} 1$ versus $\mathrm{CHO}$

Similarly, C2C12 cells with RNASET2 knockdown did not show palm-induced increases in hydrogen peroxide (Figure 5c). Given that cytoplasmic accumulation of $r p L 13 a$ snoRNAs in $\mathrm{CHO}$ cells was detected by $6 \mathrm{~h}$ of palm exposure, we hypothesize that early palm-induced superoxide (DHE signal) is likely to be a trigger for cytoplasmic snoRNA accumulation and subsequent ROS amplification (hydrogen peroxide generation as indicated by DCF signal). To test whether the RNase activity of RNASET2 is necessary for ROS production during lipotoxicity, we measured the level of hydrogen peroxide species in the 2B1-complemented clones following palm treatment (Figure $5 \mathrm{~d}$ ). Only complementation with WT RNASET2 was sufficient to restore ROS production to WT levels. Our data are consistent with a model in which catalytically active RNASET2 is necessary for the generation of ROS in response to lipotoxic stress.

Although the substrates for mammalian RNASET2 are unknown, T2 family members have been implicated in degradation of ribosomal RNA (rRNA) species in Zebrafish and transfer RNA (tRNA) species in yeast in the setting of oxidative stress. ${ }^{27,32}$ To test whether palm treatment caused degradation of rRNA, we isolated total RNA from $\mathrm{CHO}$ and 2B1 cells following palm treatment and measured $18 \mathrm{~S}$ and $28 \mathrm{~S}$ rRNA species. Although the abundance of $18 \mathrm{~S}$ rRNA was 
a

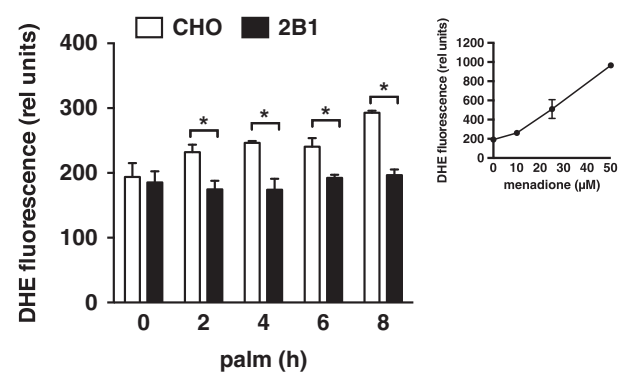

b

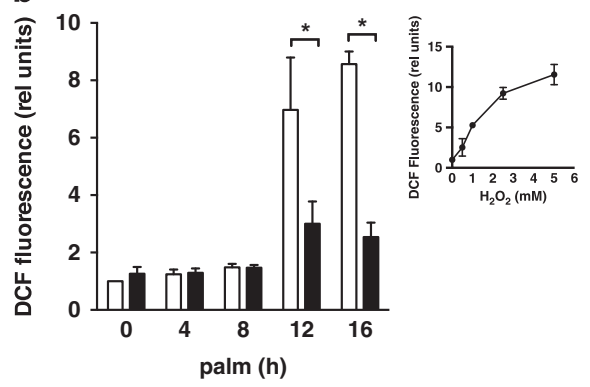

c

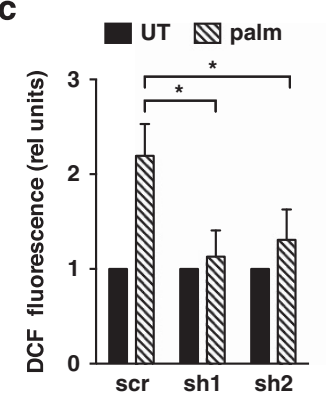

d

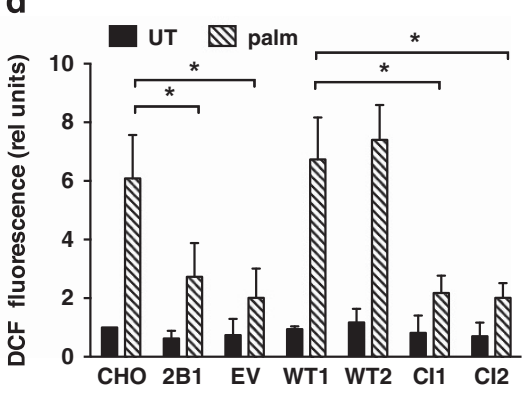

g

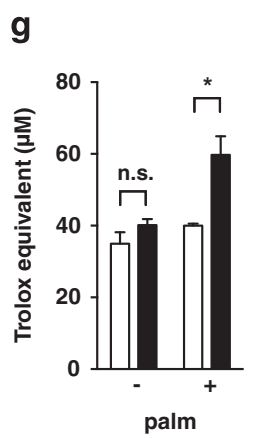

e

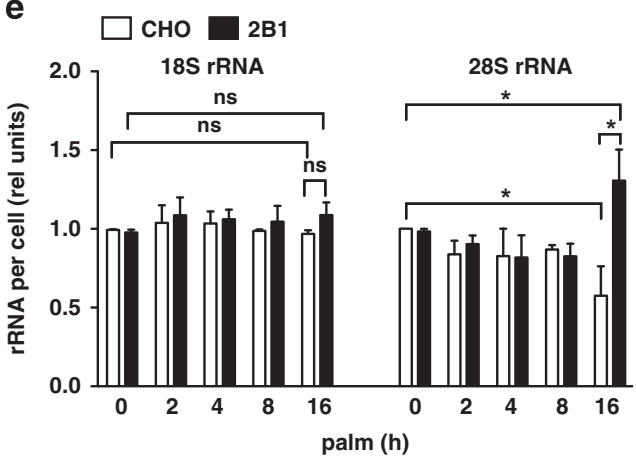

h

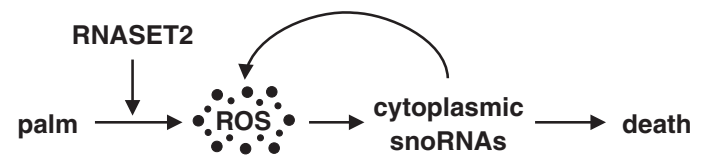

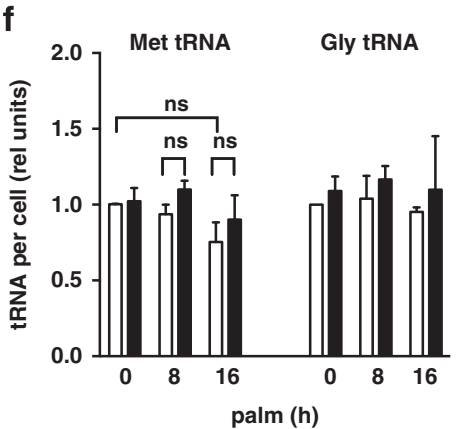

Figure 5 RNASET2 is required for induction of ROS during lipotoxicity. (a, b) $\mathrm{CHO}$ (open bars) and 2B1 (filled bars) cells were treated with palmitate for the indicated times. ROS generation was quantified by diyhdroethidium (DHE) staining and fluorescence microscopy (a) or by $2^{\prime}, 7^{\prime}$-dichlorodihydrofluorescein diacetate (DCF) staining with flow cytometry analysis of $10^{4}$ cells/sample (b). Insets show controls for detection of superoxide (a, DHE staining of $\mathrm{CHO}$ cells treated with menadione) and $\mathrm{H}_{2} \mathrm{O}_{2}(\mathbf{b}, \mathrm{DCF}$ staining of $\mathrm{CHO}$ cells treated with $\mathrm{H}_{2} \mathrm{O}_{2}$ ). (c) $\mathrm{C} 2 \mathrm{C} 12$ clonal lines transfected with shRNA sequences targeting RNASET2 or with scrambled (scr) control shRNA were treated with palm for $16 \mathrm{~h}$. ROS was quantified by DCF staining and flow cytometry analysis in untreated (filled bars) and palm-treated (hatched bars) cells. (d) Mutant 2B1 clonal lines transfected with EV or plasmids encoding WT or Cl murine RNASET2 were treated with $500 \mu \mathrm{M}$ palm for $12 \mathrm{~h}$. ROS was quantified by DCF staining and flow cytometry. (e, f) Total RNA was isolated from palm-treated $\mathrm{CHO}$ (open bars) and 2B1 (filled bars) cells. Reverse transcription with random hexamers (e) or with target-specific stem-loop primers (f) and qPCR was used to quantify rRNAs and tRNAs, respectively. (g) $\mathrm{CHO}$ (open bars) and 2B1 (filled bars) cells were untreated or treated with $500 \mu \mathrm{M}$ palm for $8 \mathrm{~h}$. Antioxidant capacity of cell lysates (50 $\mu \mathrm{g}$ protein) was quantified by Trolox equivalent antioxidant capacity (TEAC) assay. (h) Following exposure to lipotoxic conditions (palm), ROS is generated in an RNASET2-dependent manner. Downstream of ROS, rpL13a snoRNAs accumulate in the cytosol, and promote amplification of ROS. These events contribute to cell death. All graphs report mean+S.E. for $n=3$ independent experiments. ${ }^{*} P<0.05$ for comparisons indicated; ns, non-significant

unchanged by palm treatment, significant changes in the levels of $28 \mathrm{~S}$ rRNA in WT CHO and 2B1 cells were observed only after $16 \mathrm{~h}$ palm treatment (Figure $5 \mathrm{e}$ ). These late changes in $28 \mathrm{~S}$ rRNA levels were observed substantially after early ROS and snoRNA differences were detected between $\mathrm{CHO}$ and 2B1 cells. We also quantified tRNAs in the setting of lipotoxic stress. However, palm treatment did not cause depletion of several tRNA species, and we observed no difference in tRNA abundance between WT $\mathrm{CHO}$ and 2B1 cells (Figure 5f). Together, our findings suggest that the failure to produce early ROS in $2 \mathrm{~B} 1$ cells is not attributable to loss-of-function of RNASET2 in rRNA or tRNA degradation pathways.

Cells maintain their redox state by balancing generation and scavenging of ROS. ${ }^{33}$ To test whether the failure of $2 \mathrm{~B} 1$ mutant cells to increase ROS in the face of a lipotoxic challenge was related to an altered ability to scavenge free radicals, we compared the Trolox equivalent antioxidant capacity (TEAC) of lysates from $\mathrm{CHO}$ and 2B1 cells. Under basal growth conditions, there was no difference in antioxidant capacity between these cell types. However, lysates from 2B1 cells treated with palm demonstrated an $\sim 50 \%$ increase 
in measurable antioxidant capacity compared with WT CHO (Figure $5 \mathrm{~g}$ ). This suggests that haploinsufficiency of RNASET2 in 2B1 cells mitigates against lipotoxicity by enhancing the cellular antioxidant capacity (Figure 5h).

RNASET2 haploinsufficiency confers resistance to general oxidative stress. To test whether 2B1 cells were resistant to generalized $\mathrm{ROS}$, we treated $\mathrm{CHO}$ and $2 \mathrm{~B} 1$ cells with several non-lipid ROS inducers. Following exposure to hydrogen peroxide, 2B1 mutant cells failed to accumulate rpL13a snoRNAs in the cytoplasm, similar to our findings with lipotoxic stimuli (Figure 6a). We were also unable to detect amplification of ROS in 2B1 cells following exposure to hydrogen peroxide (Figure 6b). In addition, 2B1 cells were resistant to ROS following treatment with menadione, a potent inducer of superoxide (Figure 6c). Although prolonged treatment with hydrogen peroxide or menadione caused $\mathrm{CHO}$ cells to die, 2B1 cells were relatively protected
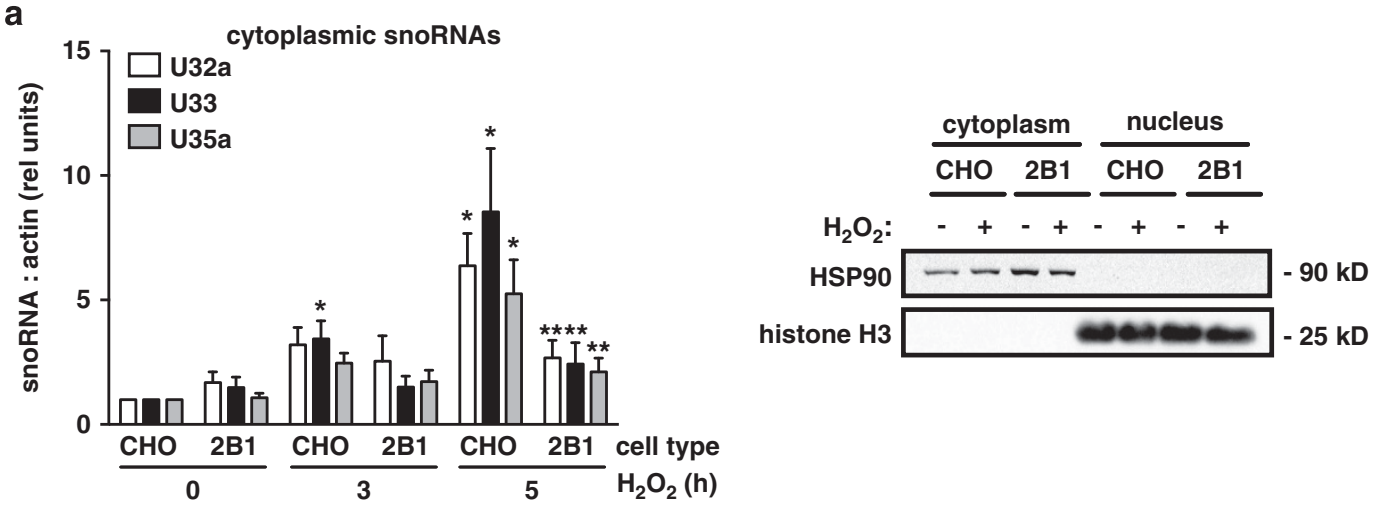

b

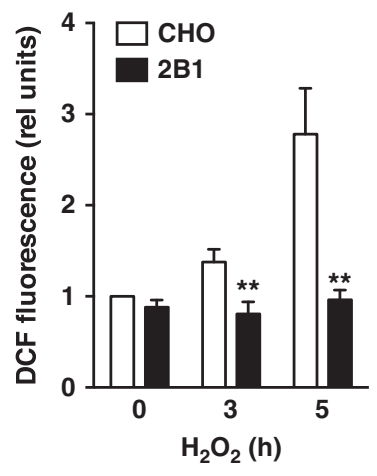

c

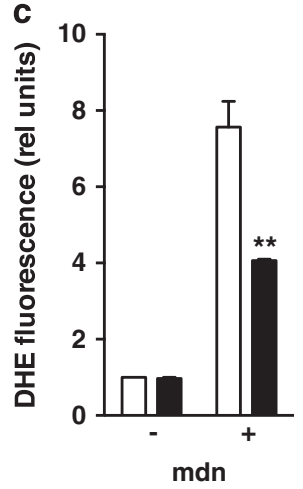

d

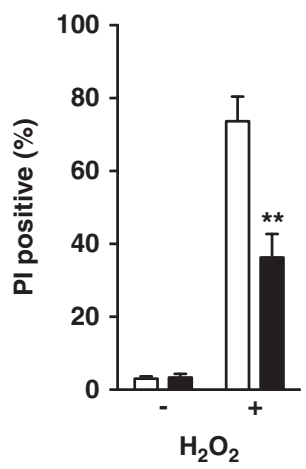

e

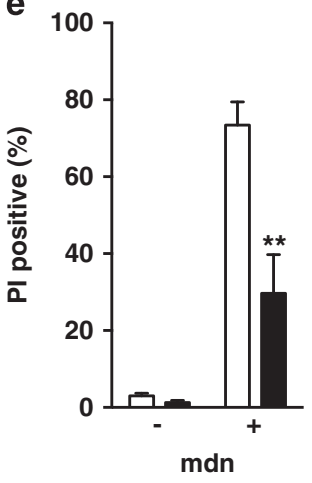

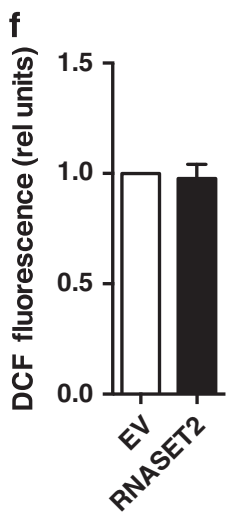

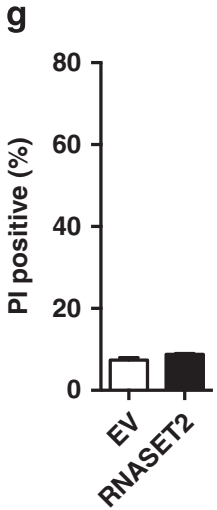

Figure $62 \mathrm{~B} 1$ cells are resistant to oxidative stress. (a, b) $\mathrm{CHO}$ and $2 \mathrm{~B} 1$ cells were treated with $1 \mathrm{mM} \mathrm{H}_{2} \mathrm{O}_{2}$ for the indicated times. Cytoplasmic RNA was isolated by sequential detergent extraction and analyzed by qRT-PCR for rpl13a snoRNAs relative to $\beta$-actin (a, left). Blots show representative western analysis for hsp90 and histone $\mathrm{H} 3 \mathrm{in}$ cytosolic and nuclear fractions at $5 \mathrm{~h}$ (a, right). ROS generation in $\mathrm{CHO}$ (open bars) and 2B1 (filled bars) cells was quantified by DCF staining and flow cytometry (b). (c) $\mathrm{CHO}$ (open bars) and 2B1 (filled bars) cells were treated with $50 \mu \mathrm{M}$ menadione ( $\mathrm{mdn}$ ) for $2 \mathrm{~h}$. ROS generation was quantified by DHE staining and flow cytometry. (d, e) CHO (open bars) and $2 \mathrm{~B} 1$ mutant (filled bars) cells were treated with $2.5 \mathrm{mM} \mathrm{H}_{2} \mathrm{O}_{2}$ for $24 \mathrm{~h}$ (d) or with $25 \mu \mathrm{M}$ menadione (mdn) for $6 \mathrm{~h}$ (e). Cell death was assayed by PI staining and flow cytometry. (f, g) $\mathrm{CHO}$ cells were transfected with empty vector (EV, open bars) or expression plasmid encoding RNASET2 (filled bars). Cells were assessed $24 \mathrm{~h}$ later for ROS by DCF staining and flow cytometric analysis (f) and for cell death by PI staining and flow cytometry (g). Graphs report mean+S.E. for a minimum of $n=3$ independent experiments. ${ }^{*} P<0.05$ for treated versus untreated; ${ }^{* \star} P<0.05$ for $2 \mathrm{~B} 1$ versus $\mathrm{CHO}$ 
(Figure $6 \mathrm{~d}$ and e). Taken together, our data suggest that RNASET2 functions upstream of propagation of ROS, and haploinsufficiency for RNASET2 protects cells broadly from oxidative stress. On the other hand, overexpression of RNASET2 in $\mathrm{CHO}$ cells in the absence of metabolic stress did not alter cellular ROS or cell death (Figure $6 f$ and $g$ ).

In vivo knockdown of RNase X25 confers survival advantage to oxidative stress. To extend our findings, we turned to the model organism Drosophila melanogaster, which is sensitive to inducers of oxidative stress. ${ }^{34}$ Drosophila expresses one RNASET2 homolog, RNase X25, which is induced by ROS and promotes cell death when overexpressed. ${ }^{28,35}$ Constitutive, whole body knockdown of RNase X25 did not result in viable progeny, underscoring the importance of RNase X25 in general housekeeping functions. However, flies with fat body-specific knockdown of RNase X25 were viable and had similar body weight to WT flies (Figure 7a). These flies demonstrated 53\% knockdown of the RNase X25 transcript by qPCR of fat body-enriched tissue, whereas two predicted off-target genes showed no difference in transcript level, indicating that knockdown was specific for RNase X25 (Figure 7b). When challenged with paraquat, an established ROS inducer in Drosophila, fat body RNase X25deficient flies had improved survival compared with WT controls (Figure 7c). To assess oxidative stress, we quantified two reporters of non-enzymatic ROS damage to proteins and lipids. ${ }^{36,37}$ RNase X25-deficient flies demonstrated $\sim 35 \%$ decreased levels of protein carbonylation under basal and stress conditions and $65 \%$ decreased levels of 7 -keto cholesterol under stress conditions (Figure $7 d$ and $e$ ). Together, our findings indicate that RNase X25 has a critical role in vivo in mediating oxidative stress-induced tissue damage and death.

\section{Discussion}

There is growing evidence that ectopic lipid accumulation in metabolic diseases contributes to impaired organ function and that lipid accumulation in non-adipose cells causes cell dysfunction and cell death. However, the molecules that link metabolic stress to cell death and organ dysfunction are poorly understood. Through a loss-of-function genetic screen, this study identified RNASET2 as a critical mediator of lipotoxic cell death. Specifically, RNASET2 is required for propagation of ROS, accumulation of non-canonical snoRNAs in the cytoplasm, and progression to cell death in response to pathophysiological levels of the saturated fatty acid, palmitate. Moreover, we demonstrate that RNASET2 is necessary for the early amplification of ROS and that haploinsufficiency of RNASET2 confers increased antioxidant capacity in cultured cells. RNASET2 is critical not only for the deleterious response to ROS in cultured fibroblasts, but also for oxidative
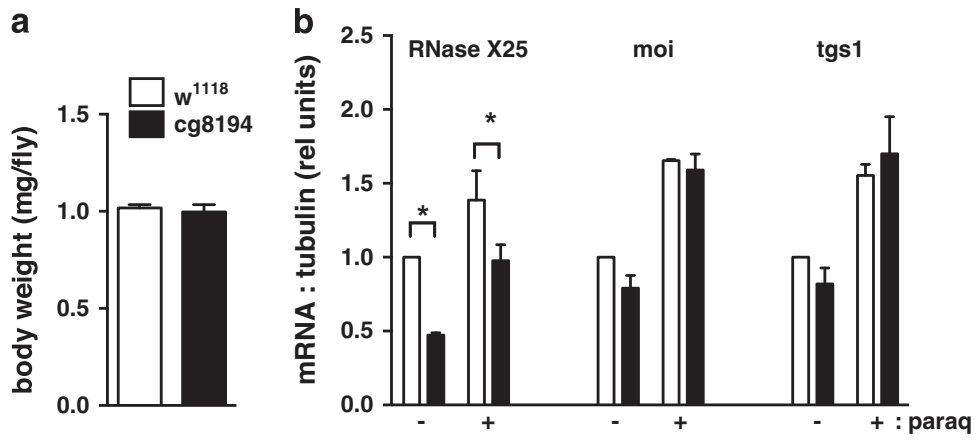

C
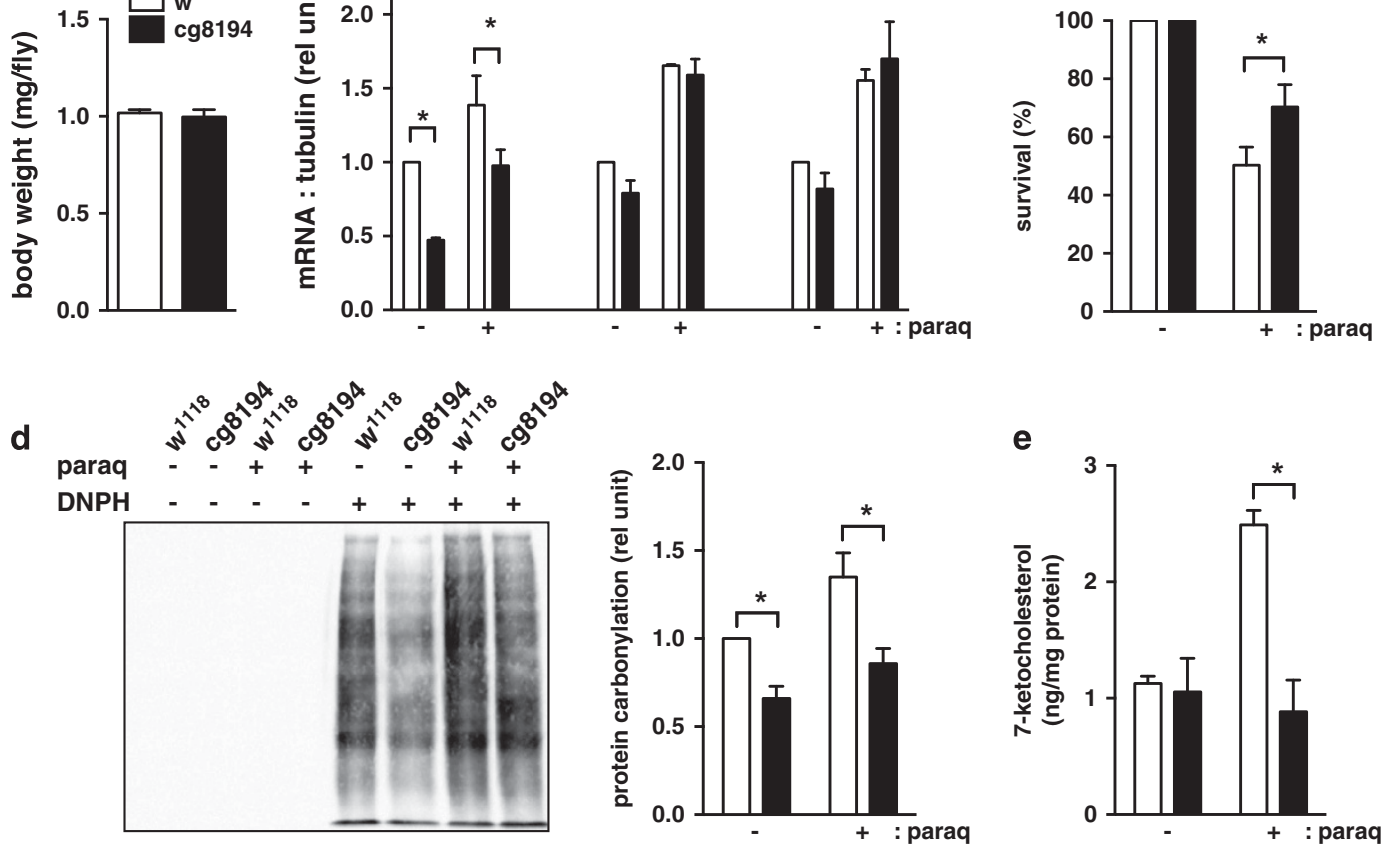

Figure 7 Knockdown of RNase X25 protects Drosophila from oxidative stress. (a) Cohorts of six female control (open bars, $w^{1118}$ ) and RNase X25 fat body knockdown (filled bars, CG8194) flies were weighed. Body weight is reported as mean weight per fly+S.E. for $n=3$ independent crosses. (b-e) Flies of each genotype were fed $5 \%$ sucrose ( - ) or $5 \%$ sucrose with $15 \mathrm{mM}$ paraquat (+) for $20 \mathrm{~h}$. Total RNA was isolated from fat body-enriched tissue of eight flies, oligo dT primed for cDNA synthesis, and expression of RNase X25, moi, and tgs 1 was determined by qRT-PCR relative to tubulin (b, graph shows mean+S.E. for $n=3$ independent crosses). Mean (+S.E.) survival at $20 \mathrm{~h}$ was quantified for 60 flies per genotype/condition in $n=3$ independent crosses (c). Extracts were prepared from fat body-enriched tissue pooled from eight flies. Carbonylated proteins were derivitized using DNPH or control solution, and analyzed by western blotting using $\alpha$-DNP antibody. Representative blot is shown (d, left) and graph (d, right) quantifies results from four independent crosses. 7-keto cholesterol was quantified in fat body lipid extracts by LC-MS/MS and is reported normalized to protein concentration (e, mean+S.E. for $n=3$ crosses). ${ }^{*} P<0.05$ for comparisons indicated 
stress-induced death in Dropsophila. These findings provide new insights into the lipotoxicity pathway and the mechanisms through which RNASET2 contributes to pathophysiological responses.

RNASET2 is a member of a family of transfer-type endonucleases that are expressed in many different species and function to cleave RNA substrates at acidic $\mathrm{pH}$ without strict base preference. ${ }^{25}$ Thompson and Parker established a link between the yeast family member, Rny1p, and oxidative stress by demonstrating that gain-of-function decreased viability in the setting of exposure to hydrogen peroxide. ${ }^{27}$ In mammalian cells, expression of RNASET2 family members is induced in response to exposure to hydrogen peroxide, ultraviolet irradiation, and inflammatory stimuli. ${ }^{28,35}$ Moreover, overexpression of this enzyme in melanocytes and keratinocytes sensitizes cells to oxidative-stress-induced apoptosis. ${ }^{28}$ Our study extends these findings in several important ways. First, we demonstrate that loss-of-function of RNASET2 protects mammalian fibroblasts from nutrient excess and generalized oxidative stress, providing the first demonstration that RNASET2 is an essential protein in mammalian cell death responses. Second, our observation that loss-of-function of RNASET2 increases cellular antioxidant capacity positions this enzyme as a novel regulator of cellular oxidative tone. Third, we show that loss-of-function of RNase X25 in Drosophila fat bodies confers increased survival in the setting of chemically induced oxidative stress, adding insight to the pathophysiological role of this enzyme.

Our results demonstrate that RNASET2 influences the cellular antioxidant capacity in response to metabolic stress upstream of cytosolic accumulation of $r p L 13 a$ snoRNAs. Thus, RNASET2 is an early mediator of signaling events during lipotoxicity. Moreover, the observation that oxidative stress is an important driver of cytosolic snoRNA accumulation is consistent with our recent work showing that NADPH oxidase-generated superoxide is a robust and rapid inducer of cytosolic snoRNA accumulation in doxorubicin-treated cells. ${ }^{38}$ Although haploinsufficiency or knockdown of RNASET2 has little effect on the basal expression of this protein, ROS levels or antioxidant capacity under homeostatic conditions, both mutant 2B1 cells and $\mathrm{C} 2 \mathrm{C} 12$ myoblasts with knockdown fail to induce RNASET2 expression during metabolic stress and propagate ROS. These findings suggest that cells tightly regulate RNASET2 expression under homeostatic conditions to maintain appropriate levels of this enzyme and that induction of RNASET2 is a critical component of cellular stress responses.

The requirement for catalytic activity of RNASET2 to complement the 2B1 mutant phenotype strongly suggests that RNASET2 limits antioxidant responses through a mechanism that involves degradation of some cellular RNA species. Consistent with reports that loss-of-function of zebrafish RNASET2 results in accumulation of rRNA species, ${ }^{32}$ RNASET2 haploinsufficient fibroblasts, unlike parental WT cells, maintain cellular rRNA levels in the setting of lipotoxic stress. However, rRNA degradation occurs late in this response in mammalian cells, and enhanced antioxidant capacity and failure to amplify ROS is detected prior to this event. We also did not detect substantial decreases in either of two tRNA species in response to lipotoxic stress. Although our studies do not rule out a contribution of RNASET2 to degradation of rRNA or other tRNAs in the lipotoxic response pathway, we hypothesize that the effects of RNASET2 on antioxidant capacity likely involve its ability to target RNA species other than rRNAs and tRNAs. The requirement for enzymatic activity of RNASET2 in lipotoxic cell death contrasts with studies showing that CI RNASET2 inhibits tumorigenesis of ovarian tumor cell lines and amplifies apoptotic cell death in response to hydrogen peroxide when overexpressed in melanocytes and keratinocytes. ${ }^{28,39}$ Emerging evidence that other RNases regulate gene expression post-transcriptionally through targeted mRNA degradation suggests the possibility that RNASET2 substrates could include mRNAs involved in antioxidant responses. ${ }^{40-42}$ Identification of the relevant RNASET2 substrates in future studies will provide important insights into its impact on cellular oxidative stress responses.

RNASET2 has not been demonstrated to cleave substrates with base specificity. However, modification by mannose-6phosphate residues, subcellular fraction studies, and an acidic $\mathrm{pH}$ optimum indicate that RNASET2 resides in the lysosomes of mammalian cells, where selectivity of RNA degradation may be maintained by both the physical and chemical environment. $^{30,43}$ In contrast to the yeast Rny1p, which localizes to the vacuole but is released to the cytoplasm on oxidative stress, ${ }^{27}$ we did not detect mammalian RNASET2 in the soluble, cytoplasmic fraction of $\mathrm{CHO}$ cells following lipotoxic or oxidative stress (not shown). Rather, RNASET2 likely functions in these pathways within the lysosomal lumen, where it may encounter RNA substrates delivered by lipidinduced microautophagy, mitophagy and ribophagy. ${ }^{44,45}$ RNASET2 may be targeted directly to lysosomes by trafficking from the Golgi to the endosomal system; ${ }^{46}$ however, evidence that RNASET2 is secreted and subsequently taken up by target cells raises the possibility that this enzyme may also traffic to the lysosome indirectly from the plasma membrane following endocytosis. ${ }^{30,39}$

Prior studies have established roles for RNASET2 in tumor progression, vitiligo, and neurodevelopmental development abnormalities. ${ }^{32,39,47}$ Our study provides new insights into the function of this lysosomal enzyme as a regulator of pathophysiological oxidative stress responses and adds to a growing body of evidence that the lysosome and its components are essential for integrating a wide array of metabolic stimuli into cell fate decisions. ${ }^{48,49}$ Future studies to establish the precise substrates of RNASET2 will shed important light on the mechanisms through which it functions to control cellular oxidative tone.

\section{Materials and Methods}

Materials. Palmitate was from Nu-Check Prep (Waterville, MN, USA). Actinomycin $D$ and OxyBlot Protein Oxidation Detection Kit were from Millipore (Billerica, MA, USA). Staurosporine, hydrogen peroxide, Trolox, 2,2'-azinobis-(3ethylbenzothiazoline-6-sulfonic acid) (ABTS), paraquat, and menadione were from Sigma-Aldrich (St. Louis, MO, USA). Fatty acid-free bovine serum albumin (BSA) was from SeraCare (Milford, MA, USA). Hygromycin B, BODIPY FL $C_{16}(4,4-$ difluoro-5,7-dimethyl-4-bora-3a,4a-diaza-s-indacene-3-hexadecanoic acid) D-3821 (BODIPY FA), PI, DHE, Trizol, 2',7'-DCF, and lipofectamine were from Life Technologies (Carlsbad, CA, USA). Purified Torulla yeast RNA was from Ambion (Carlsbad, CA, USA). All synthetic oligonucleotides were from Integrated DNA Technologies (Coralville, IA, USA). Restriction enzymes were from New England BioLabs (Ipswich, MA, USA). 
Cells. CHO K1 cells (American Type Culture Collection, ATCC) and CHO-derived cell lines were maintained in high-glucose $(4.5 \mathrm{mg} / \mathrm{ml}$ Dulbecco's modified Eagle's medium and Ham's F-12 nutrient mixture (1:1)) medium with $5 \%$ non-inactivated fetal calf serum, $2 \mathrm{mM}$ L-glutamine, 50 units/ $/ \mathrm{ml}$ penicillin $\mathrm{G}$ sodium, 50 units $/ \mathrm{ml}$ streptomycin sulfate, and $0.5 \mathrm{mM}$ sodium pyruvate. $\mathrm{C} 2 \mathrm{C} 12$ murine myoblast cells (ATCC) were maintained in Dulbecco's modified Eagle's medium supplemented with $10 \%(\mathrm{v} / \mathrm{v})$ heat-inactivated fetal calf serum, $2 \mathrm{mM}$ glutamine, $50 \mathrm{U} / \mathrm{ml}$ penicillin, and $50 \mu \mathrm{g} / \mathrm{ml}$ streptomycin. For lipotoxicity experiments, medium was supplemented with $500 \mu \mathrm{M}$ palm complexed to BSA at a 2:1 molar ratio, as described previously. ${ }^{18}$ For ROS induction, medium was supplemented with the indicated concentrations of hydrogen peroxide or menadione.

Genetic screen. CHO cells were transduced with vesicular stomatitis virus $G$ protein-pseudotyped murine retrovirus containing the ROSA $\beta$ geo retroviral promoter trap at a low multiplicity of infection, as previously described. ${ }^{24}$ Retroviral insertion into the genome was assessed by Southern blotting. The gene disrupted by retroviral insertion was identified by $5^{\prime}$ RACE using an oligonucleotide tag and ROSA $\beta$ geo sequences (SMART RACE cDNA amplification kit; Clonetech, Mountain View, CA, USA). The 5' RACE product was TA-cloned, sequenced, and analyzed by NCBI BLAST.

Fatty acid uptake assay. Fluorescent fatty acid uptake was performed as described. ${ }^{50}$ In brief, cells were trypsinized, washed in media, and incubated at $37^{\circ} \mathrm{C}$ for $1 \mathrm{~min}$ in fatty acid uptake solution $(20 \mu \mathrm{M}$ fatty acid-free BSA and $6 \mu \mathrm{M}$ BODIPY-3821). Cells were washed at $4{ }^{\circ} \mathrm{C}$, pelleted, resuspended in media, and mean fluorescence was determined by flow cytometry ( $10^{4}$ cells/sample).

Transient transfections. The murine RNASET2 cDNA sequence was cloned by PCR downstream of $2 \mathrm{~kb}$ of the genomic murine RNASET2 promoter into pcDNA3.1(-)hygro. QuikChange II Site-directed Mutagenesis (Stratagene, La Jolla, $\mathrm{CA}$, USA) was used to create the $\mathrm{Cl}$ construct $(\mathrm{H} 117 \mathrm{~F} / \mathrm{H} 122 \mathrm{~F})$. Cells were transfected with Lipofectamine Plus according to the manufacturer's instructions and assayed $20 \mathrm{~h}$ post transfection.

Stable cell lines. siRNAs to murine RNASET2 were designed (Ambion's siRNA Target Finder Program), tested in transient transfections, and corresponding shRNA oligonucleotides were designed and cloned into a pSilencer4.1-CMVneo (Ambion). Constructs were nucleofected into $\mathrm{C} 2 \mathrm{C} 12$ cells (Amaxa nucleofector kit $\mathrm{V}$,

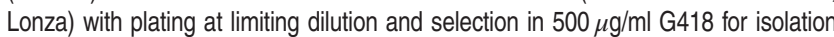
of stable clonal lines. Full-length genomic or $\mathrm{Cl}$ murine RNASET2, including $4.3 \mathrm{~Kb}$ upstream and $1.5 \mathrm{~Kb}$ downstream, was recombineered into pcDNA3.1(-)neo. Mutant 2B1 cells were stably transfected with Lipofectamine Plus reagent, plated at limiting dilutions in $300 \mu \mathrm{g} / \mathrm{ml}$ hygromycin, and clonal lines were isolated.

Cell death. Cell death was assessed by membrane permeability to $1 \mu \mathrm{M} \mathrm{PI}$ and flow cytometry analysis. Apoptosis was assessed by simultaneous annexin V-EGFP and $\mathrm{PI}$ staining with flow cytometry quantification annexin $\mathrm{V}^{+} / \mathrm{PI}^{-}$cells. For flow analyses, mean fluorescence was quantified on of $10^{4}$ cells/sample.

QRT-PCR. RNA was isolated using TRIzol or TRIzol LS reagent and reverse transcribed to cDNA (SuperScript III First-Strand Synthesis System, Life Technologies) by priming with oligo(dT) to detect mRNA or random hexamers to detect pre-mRNA, intron lariats, and ribosomal RNA. For detection of snoRNAs and tRNAs, cDNA synthesis was primed with hairpin stem-loop oligonucleotides as previously described, ${ }^{22}$ with overhang complementarity to the $3^{\prime}$ end of the processed snoRNA or tRNA. For detection of rRNA, RNA was extracted and reverse transcribed using random hexamers, normalizing per cell number. For all RNA species, cDNA was amplified for 40 PCR cycles using SYBR green PCR master mix (Applied Biosystems) and $100 \mathrm{nM}$ template-specific primers in an $\mathrm{ABI}$ Prism 7500 Fast real-time PCR system. Relative quantification of gene expression was performed using the comparative threshold method.

Generation of the RNASET2 antibody. Affinity purified polyclonal rabbit anti-peptide antibody was generated against $\mathrm{NH}_{2}$-DGPIFYPPPTKTQH-OH (murine sequence, amino acids 246-259).

Immunoblot assays. Whole-cell protein lysates were prepared using RIPA buffer (50mMTris- $\mathrm{Cl}, 150 \mathrm{mMNaCl}, 1 \%$ Nonidet P-40, 0.5\% sodium deoxycholate, $0.1 \%$ SDS, and $5 \mathrm{mM}$ EDTA) containing $1 \mathrm{mM}$ phenylmethylsulfonyl fluoride and $1 \times$
Protease Complete inhibitor mixture (Roche, Basel, Switzerland). Subcellular fractions were isolated by sequential detergent solubilization as described previously. ${ }^{51}$ Proteins were resolved by SDS-PAGE, transferred to nitrocellulose membranes (Whatman), and probed with antibodies to RNASET2 (1:500), $\beta$-actin (A2066; 1: 5,000; Sigma, St. Louis, MO, USA), and hsp90 (SPA-846; 1:2,000; Stressgen, Farmingdale, NY, USA). Proteins were visualized using horseradish peroxidase-conjugated secondary antibodies (Jackson ImmunoResearch Laboratories, West Grove, PA, USA; 1:10000) and chemiluminescence reagents (PerkinElmer Life Sciences, Waltham, MA, USA). A representative blot is shown for each experiment.

Assessment of catalytic activity of RNASET2 constructs. Zymography was performed as described. ${ }^{30}$

Detection of ROS. Following treatments as indicated, cells were rinsed with PBS and incubated at $37^{\circ} \mathrm{C}$ in the dark with PBS containing $0.5 \mathrm{mM} \mathrm{MgCl}$, $0.92 \mathrm{mM} \mathrm{CaCl}_{2}$, and either $3 \mu \mathrm{M} \mathrm{DCF}$ for $1 \mathrm{~h}$ or $10 \mu \mathrm{M} \mathrm{DHE}$ for $15 \mathrm{~min}$. The cells were recovered by trypsinization, and mean fluorescence was determined by flow cytometry $\left(10^{4}\right.$ cells/sample). For DHE detection by microscopy, cells were grown on gelatin-treated glass coverslips and stained for DHE as above. In each independent experiment, DHE fluorescence of 20 cells per field in five random fields was quantified using AxioVision software.

TEAC assay. Antioxidant capacity was assessed by TEAC assay as previously described. $^{52}$

Drosophila studies. Flies were maintained at $25^{\circ} \mathrm{C}$ on molasses-based fly food. The following stocks were used: $w^{1118}$ (VRDC 60100), cgGal4 (Bloomington 7011), UAS-CG8194 RNAi (VRDC 13018). To generate fat body RNase X25 knockdown, we crossed UAS-CG8194 RNAi males with cgGal4 virgin females. For paraquat treatment studies 1-week-old female flies were maintained on agar supplemented with $5 \%$ sucrose in PBS for $4 \mathrm{~h}$. Then, flies were transferred to vials containing either agar with $5 \%$ sucrose or agar with $5 \%$ sucrose and $15 \mathrm{mM}$ paraquat (20 flies/vial, three vials each condition for three independent crosses). Live flies were counted after $20 \mathrm{~h}$. Oxidative stress signatures were assessed after $20 \mathrm{~h}$ of paraquat treatment. To obtain fat bodyenriched tissue, we dissected flies and processed the abdominal cuticle with fat body still attached for RNA, protein extraction, and lipid extraction. Carbonylated proteins were analyzed using OxyBlot Protein Oxidation Detection Kit per manufacturer's instructions. 7-keto cholesterol was quantified by LC-MS/MS as previously described. ${ }^{37}$

Statistics. Data were analyzed using ANOVA for multiple comparisons or $t$-test for pairwise comparisons. Statistical significance is indicated for $P<0.05$.

\section{Conflict of Interest}

The authors declare no conflict of interest.

Acknowledgements. This work was supported by grants from the NIH (5 R01 DK064989 to JES; T32 HL007275, and 5P30 DK020579).

1. Browning JD, Horton JD. Molecular mediators of hepatic steatosis and liver injury. J Clin Invest 2004; 114: 147-152.

2. Shulman Gl. Cellular mechanisms of insulin resistance. J Clin Invest 2000; 106: 171-176.

3. Robertson RP, Harmon J, Tran PO, Poitout V. Beta-cell glucose toxicity, lipotoxicity, and chronic oxidative stress in type 2 diabetes. Diabetes 2004; 53(Suppl 1): S119-S124.

4. Goldberg IJ, Trent CM, Schulze PC. Lipid metabolism and toxicity in the heart. Cell Metab 2012; 15: 805-812.

5. Busch AK, Cordery D, Denyer GS, Biden TJ. Expression profiling of palmitate- and oleateregulated genes provides novel insights into the effects of chronic lipid exposure on pancreatic beta-cell function. Diabetes 2002; 51: 977-987.

6. Cnop M, Abdulkarim B, Bottu G, Cunha DA, Igoillo-Esteve M, Masini M et al. RNA sequencing identifies dysregulation of the human pancreatic islet transcriptome by the saturated fatty acid palmitate. Diabetes 2014; 63: 1978-1993.

7. Cacicedo JM, Benjachareowong S, Chou E, Ruderman NB, Ido Y. Palmitate-induced apoptosis in cultured bovine retinal pericytes: roles of $\mathrm{NAD}(\mathrm{P}) \mathrm{H}$ oxidase, oxidant stress, and ceramide. Diabetes 2005; 54: 1838-1845. 
8. Eitel $\mathrm{K}$, Staiger $\mathrm{H}$, Rieger J, Mischak H, Brandhorst $\mathrm{H}$, Brendel MD et al. Protein kinase $\mathrm{C}$ delta activation and translocation to the nucleus are required for fatty acid-induced apoptosis of insulin-secreting cells. Diabetes 2003; 52: 991-997.

9. Cazanave SC, Mott JL, Bronk SF, Werneburg NW, Fingas CD, Meng XW et al. Death receptor 5 signaling promotes hepatocyte lipoapoptosis. J Biol Chem 2011; 286: 39336-39348.

10. Liu L, Zhang Y, Chen N, Shi X, Tsang B, Yu YH. Upregulation of myocellular DGAT1 augments triglyceride synthesis in skeletal muscle and protects against fat-induced insulin resistance. J Clin Invest 2007; 117: 1679-1689.

11. Pulinilkunnil T, Kienesberger PC, Nagendran J, Waller TJ, Young ME, Kershaw EE et al. Myocardial adipose triglyceride lipase overexpression protects diabetic mice from the development of lipotoxic cardiomyopathy. Diabetes 2013; 62: 1464-1477.

12. Ostrander DB, Sparagna GC, Amoscato AA, McMillin JB, Dowhan W. Decreased cardiolipin synthesis corresponds with cytochrome $\mathrm{C}$ release in palmitate-induced cardiomyocyte apoptosis. J Biol Chem 2001; 276: 38061-38067.

13. Cnop M, Hannaert JC, Hoorens A, Eizirik DL, Pipeleers DG. Inverse relationship between cytotoxicity of free fatty acids in pancreatic islet cells and cellular triglyceride accumulation. Diabetes 2001; 50: 1771-1777.

14. Cnop M, Ladriere L, Hekerman P, Ortis F, Cardozo AK, Dogusan Z et al. Selective inhibition of eukaryotic translation initiation factor 2 alpha dephosphorylation potentiates fatty acidinduced endoplasmic reticulum stress and causes pancreatic beta-cell dysfunction and apoptosis. J Biol Chem 2007; 282: 3989-3997.

15. Inoguchi T, Li P, Umeda F, Yu HY, Kakimoto M, Imamura M et al. High glucose level and free fatty acid stimulate reactive oxygen species production through protein kinase $\mathrm{C}$-dependent activation of NAD(P)H oxidase in cultured vascular cells. Diabetes 2000; 49: 1939-1945.

16. Gao D, Nong S, Huang X, Lu Y, Zhao H, Lin Y et al. The effects of palmitate on hepatic insulin resistance are mediated by NADPH Oxidase 3-derived reactive oxygen species through JNK and p38MAPK pathways. J Biol Chem 2010; 285: 29965-29973.

17. Yang W, Tanaka Y, Bundo M, Hirokawa N. Antioxidant signaling involving the microtubule motor KIF12 is an intracellular target of nutrition excess in beta cells. Dev Cell 2014; 31: 202-214.

18. Listenberger LL, Ory DS, Schaffer JE. Palmitate-induced apoptosis can occur through a ceramide-independent pathway. J Biol Chem 2001; 276: 14890-14895.

19. Lee Y, Naseem RH, Park BH, Garry DJ, Richardson JA, Schaffer JE et al. Alpha-lipoic acid prevents lipotoxic cardiomyopathy in acyl CoA-synthase transgenic mice. Biochem Biophys Res Commun 2006; 344: 446-452.

20. Nishikawa T, Edelstein D, Du XL, Yamagishi S, Matsumura T, Kaneda Y et al. Normalizing mitochondrial superoxide production blocks three pathways of hyperglycaemic damage. Nature 2000; 404: 787-790.

21. Huang A, Yang YM, Yan C, Kaley G, Hintze TH, Sun D. Altered MAPK signaling in progressive deterioration of endothelial function in diabetic mice. Diabetes 2012; 61: 3181-3188.

22. Michel Cl, Holley CL, Scruggs BS, Sidhu R, Brookheart RT, Listenberger LL et al. Small nucleolar RNAs U32a, U33, and U35a are critical mediators of metabolic stress. Cell Metab 2011; 14: 33-44.

23. Scruggs BS, Michel $\mathrm{Cl}$, Ory DS, Schaffer JE. SmD3 regulates intronic noncoding RNA biogenesis. Mol Cell Biol 2012; 32: 4092-4103.

24. Borradaile NM, Buhman KK, Listenberger LL, Magee CJ, Morimoto ET, Ory DS et al. A critical role for eukaryotic elongation factor 1A-1 in lipotoxic cell death. Mol Biol Cell 2006; 17: 770-778.

25. Luhtala N, Parker R. T2 Family ribonucleases: ancient enzymes with diverse roles. Trends Biochem Sci 2010; 35: 253-259.

26. McCubbin AG, Chung YY, Kao T. A mutant S3 RNase of petunia inflata lacking RNase activity has an allele-specific dominant negative effect on self-incompatibility interactions. Plant Cell 1997; 9: 85-95.

27. Thompson DM, Parker R. The RNase Rny1p cleaves tRNAs and promotes cell death during oxidative stress in Saccharomyces cerevisiae. J Cell Biol 2009; 185: 43-50.

28. Wang Q, Jiang M, Wu J, Ma Y, Li T, Chen Q et al. Stress-induced RNASET2 overexpression mediates melanocyte apoptosis via the TRAF2 pathway in vitro. Cell Death Dis 2014; 5 e1022.

29. Ohgi $\mathrm{K}$, Horiuchi $\mathrm{H}$, Watanabe $\mathrm{H}$, Iwama $\mathrm{M}$, Takagi $\mathrm{M}$, Irie M. Role of Asp51 and Glu105 in the enzymatic activity of a ribonuclease from Rhizopus niveus. J Biochem 1993; 113: 219-224.
30. Campomenosi $\mathrm{P}$, Salis S, Lindqvist $\mathrm{C}$, Mariani $\mathrm{D}$, Nordstrom T, Acquati $\mathrm{F}$ et al Characterization of RNASET2, the first human member of the Rh/T2/S family of glycoproteins. Arch Biochem Biophys 2006; 449: 17-26.

31. Brookheart RT, Michel Cl, Listenberger LL, Ory DS, Schaffer JE. The non-coding RNA gadd7 is a regulator of lipid-induced oxidative and endoplasmic reticulum stress. J Biol Chem 2009; 284: 7446-7454.

32. Haud N, Kara F, Diekmann S, Henneke M, Willer JR, Hillwig MS et al. rnaset2 mutant zebrafish model familial cystic leukoencephalopathy and reveal a role for RNase T2 in degrading ribosomal RNA. Proc Natl Acad Sci USA 2011; 108: 1099-1103.

33. Preiser J. Oxidative stress. JPEN J Parenter Enteral Nutr 2012; 36: 147-154.

34. Mehdi SH, Qamar A. Paraquat-induced ultrastructural changes and DNA damage in the nervous system is mediated via oxidative-stress-induced cytotoxicity in Drosophila melanogaster. Toxicol Sci 2013; 134: 355-365

35. Ambrosio L, Morriss S, Riaz A, Bailey R, Ding J, Maclntosh GC. Phylogenetic analyses and characterization of RNase X25 from Drosophila melanogaster suggest a conserved housekeeping role and additional functions for RNase T2 enzymes in protostomes. PLOS One 2014; 9: e105444.

36. Zhang JR, Coleman T, Langmade SJ, Scherrer DE, Lane L, Lanier MH et al. Niemann-Pick C1 protects against atherosclerosis in mice via regulation of macrophage intracellular cholesterol trafficking. J Clin Invest 2008; 118: 2281-2290.

37. Porter FD, Scherrer DE, Lanier MH, Langmade SJ, Molugu V, Gale SE et al. Cholestero oxidation products are sensitive and specific blood-based biomarkers for Niemann-Pick C1 disease. Sci Transl Med 2010; 2: 56ra81.

38. Holley CL, Li MW, Scruggs BS, Matkovich SJ, Ory DS, Schaffer JE. Cytosolic accumulation of small nucleolar RNAs (snoRNAs) is dynamically regulated by NADPH oxidase. $J$ Biol Chem 2015; 290: 11741-11748.

39. Acquati F, Bertilaccio S, Grimaldi A, Monti L, Cinquetti R, Bonetti P et al. Microenvironmental control of malignancy exerted by RNASET2, a widely conserved extracellular RNase. Proc Natl Acad Sci USA 2011; 108: 1104-1109.

40. Brennan-Laun SE, Li XL, Ezelle HJ, Venkataraman T, Blackshear PJ, Wilson GM et al. RNase $L$ attenuates mitogen-stimulated gene expression via transcriptional and posttranscriptional mechanisms to limit the proliferative response. J Biol Chem 2014; 289 33629-33643.

41. Zhang Q, Siegel TN, Martins RM, Wang F, Cao J, Gao $Q$ et al. Exonuclease-mediated degradation of nascent RNA silences genes linked to severe malaria. Nature 2014; 513 431-435.

42. Fabre O, Breuker C, Amouzou C, Salehzada T, Kitzmann M, Mercier J et al. Defects in TLR3 expression and RNase $\mathrm{L}$ activation lead to decreased MnSOD expression and insulin resistance in muscle cells of obese people. Cell Death Dis 2014; 5: e1136.

43. Sleat DE, Della Valle MC, Zheng H, Moore DF, Lobel P. The mannose 6-phosphate glycoprotein proteome. J Proteome Res 2008; 7: 3010-3021.

44. Kraft C, Deplazes A, Sohrmann M, Peter M. Mature ribosomes are selectively degraded upon starvation by an autophagy pathway requiring the Ubp3p/Bre5p ubiquitin protease. Nat Cell Biol 2008; 10: 602-610.

45. Zhu J, Wang KZ, Chu CT. After the banquet: mitochondrial biogenesis, mitophagy, and cell survival. Autophagy 2013; 9: 1663-1676.

46. Vidalino L, Monti L, Haase A, Moro A, Acquati F, Taramelli R et al. Intracellular trafficking of RNASET2, a novel component of P-bodies. Biol Cell 2012; 104: 13-21.

47. Henneke M, Diekmann S, Ohlenbusch A, Kaiser J, Engelbrecht V, Kohlschutter A et al. RNASET2-deficient cystic leukoencephalopathy resembles congenital cytomegalovirus brain infection. Nat Genet 2009; 41: 773-775.

48. Zoncu R, Efeyan A, Sabatini DM. mTOR: from growth signal integration to cancer, diabetes and ageing. Nat Rev Mol Cell Biol 2011; 12: 21-35.

49. Settembre C, Fraldi A, Medina DL, Ballabio A. Signals from the lysosome: a control centre for cellular clearance and energy metabolism. Nat Rev Mol Cell Biol 2013; 14: 283-296.

50. Richards MR, Harp JD, Ory DS, Schaffer JE. Fatty acid transport protein 1 and long-chain acyl coenzyme A synthetase 1 interact in adipocytes. J Lipid Res 2006; 47: 665-672.

51. Holden $\mathrm{P}$, Horton WA. Crude subcellular fractionation of cultured mammalian cell lines. BMC Res Notes 2009; 2: 243

52. Re R, Pellegrini N, Proteggente A, Pannala A, Yang M, Rice-Evans C. Antioxidant activity applying an improved ABTS radical cation decolorization assay. Free Radic Biol Med 1999; 26: $1231-1237$. 